\title{
Comparison of the Binding Stoichiometries of Positively Charged DNA-Binding Drugs Using Positive and Negative Ion Electrospray Ionization Mass Spectrometry
}

\author{
Rajesh Gupta, Jennifer L. Beck, Stephen F. Ralph, and Margaret M. Sheil \\ Department of Chemistry, University of Wollongong, Wollongong, New South Wales, Australia
}

Janice R. Aldrich-Wright

School of Science, Food and Horticulture, Campbelltown Campus, University of Western Sydney, New South Wales, Australia

Positive and negative ion electrospray ionization (ESI) mass spectra of complexes of positively charged small molecules (distamycin, Hoechst 33258, [Ru(phen) $\left.{ }_{2} \mathrm{dpq}\right] \mathrm{Cl}_{2}$ and $\left[\mathrm{Ru}(\mathrm{phen})_{2} \mathrm{dpqC}\right] \mathrm{Cl}_{2}$ ) have been compared. $\left[\mathrm{Ru}(\mathrm{phen})_{2} \mathrm{dpq}\right] \mathrm{Cl}_{2}$ and $\left[\mathrm{Ru}(\mathrm{phen})_{2} \mathrm{dpqC}\right] \mathrm{Cl}_{2}$ bind to DNA by intercalation. Negative ion ESI mass spectra of mixtures of $\left[\mathrm{Ru}(\mathrm{phen})_{2} \mathrm{dpq}\right] \mathrm{Cl}_{2}$ or $\left[\mathrm{Ru}(\mathrm{phen})_{2} \mathrm{dpqC}\right] \mathrm{Cl}_{2}$ with DNA showed ions from DNA-ligand complexes consistent with solution studies. In contrast, only ions from free DNA were present in positive ion ESI mass spectra of mixtures of $\left[\mathrm{Ru}(\mathrm{phen})_{2} \mathrm{dpq}\right] \mathrm{Cl}_{2}$ or $\left[\mathrm{Ru}(\mathrm{phen})_{2} \mathrm{dpqC}\right] \mathrm{Cl}_{2}$ with DNA, highlighting the need for obtaining ESI mass spectra of non-covalent complexes under a range of experimental conditions. Negative ion spectra of mixtures of the minor groove binder Hoechst 33258 with DNA containing a known minor groove binding sequence were dominated by ions from a 1:1 complex. In contrast, in positive ion spectra there were also ions present from a 2:1 (Hoechst 33258: DNA) complex, suggesting an alternative binding mode was possible either in solution or in the gas phase. When Hoechst 33258 was mixed with a DNA sequence lacking a high affinity minor groove binding site, the negative ion ESI mass spectra showed that 1:1 and 2:1 complexes were formed, consistent with existence of binding modes other than minor groove binding. The data presented suggest that comparison of positive and negative ion ESI-MS spectra might provide an insight into various binding modes in both solution and the gas phase. (J Am Soc Mass Spectrom 2004, 15, 1382-1391) (c) 2004 American Society for Mass Spectrometry

$\mathrm{N}$ ucleic acids are increasingly the targets for drug therapies. Drugs may interact directly with DNA inhibiting the growth of microorganisms or tumors, or they may affect gene expression by interfering with the binding of transcription factors (proteins) to regulatory sequences of DNA [1]. It has been estimated that in order to specifically target a unique regulatory sequence within a gene in the human genome, eleven DNA base pairs have to be recognized by a drug [2]. Consequently, efforts have been directed towards the synthesis of novel compounds, often based on natural products that interact non-covalently with extended DNA sequences that have particular characteristics (e.g., ATrich promoters of genes). Drugs that bind non-covalently,

Published online August 27, 2004

Address reprint requests to: Prof. Margaret Sheil, Department of Chemistry and Vice-Chancellors Unit, University of Wollongong, Northfields Avenue, Wollongong, 2522, New South Wales, Australia. E-mail: msheil@uow. edu.au. but with relatively high affinity to DNA include minor groove-binders and intercalators [1].

Minor groove-binders are crescent-shaped molecules with potential $\mathrm{H}$-bonding groups on their concave edge [3]. They have a high affinity for AT-rich sequences, and are often positively charged. Examples of this class of drug are Hoechst 33258 and distamycin (Hc and Dm, respectively; Figure 1a and b). Intercalators are planar aromatic polycyclic compounds that slide between stacked base pairs of the DNA double helix [1]. Substitution on the aromatic rings can confer enhanced specificity to the drug-DNA interaction. For example, the sugar moiety of daunomycin, a widely used antitumor agent, can H-bond with atoms on the outside of the helix [4].

As a first-pass evaluation of new drugs that may be more sequence-selective in their interactions with DNA, it will be useful to develop methods for rapid and sensitive screening. Electrospray ionization mass spec- 
(a)

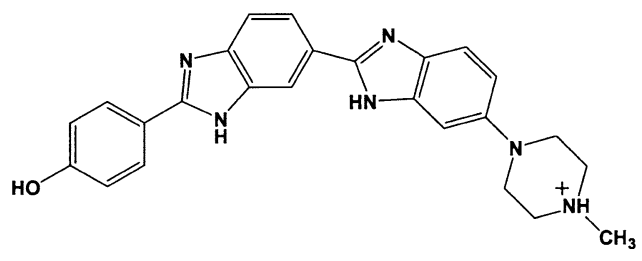

(b)

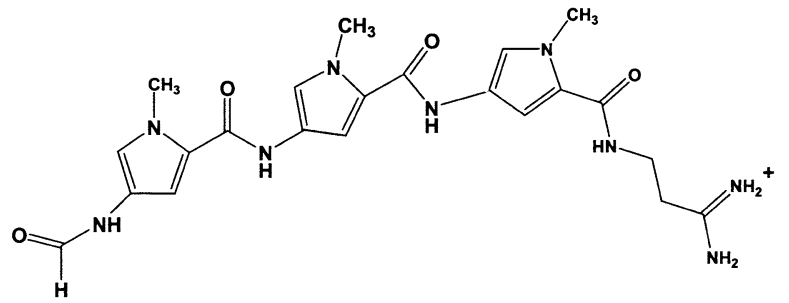

(c)
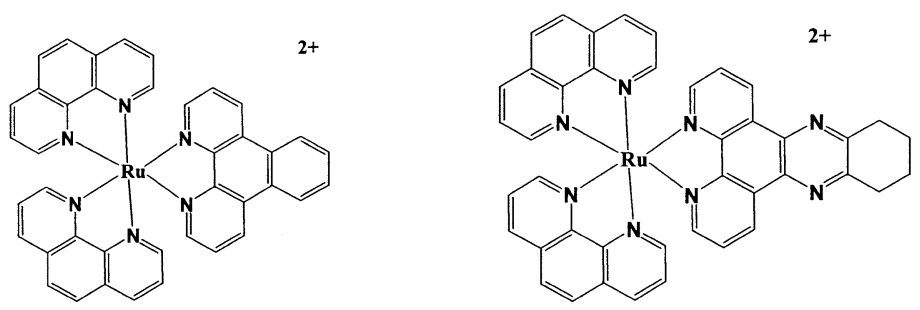

(d)

Figure 1. Structures of: the minor groove-binders, (a) Hoechst $33258(\mathrm{Hc}),(\mathbf{b})$ distamycin $(\mathrm{Dm})$; the intercalators, (c) $\left[\mathrm{Ru}(\text { phen })_{2}(\mathrm{dpq})\right] \mathrm{Cl}_{2}$, (d) $\left[\mathrm{Ru}(\text { phen })_{2}(\mathrm{dpqC})\right] \mathrm{Cl}_{2}$.

trometry (ESI-MS) has substantial potential for this purpose. Several research groups have used ESI-MS to assess the relative affinities and stoichiometries of drugs that bind to DNA $[5,6]$. Although many noncovalent complexes have been studied by ESI-MS, questions remain as to the extent to which complexes detected in the gas phase reflect the solution equilibrium position existing prior to injection into the mass spectrometer [7-9]. There are at least three possibilities to consider under a given set of experimental conditions: (i) the abundances and stoichiometries of the complexes are a snapshot of the complexes present in solution, (ii) the complexes may not be stable during ionization or transmission through the mass spectrometer, and (iii) during the ionization/desolvation process, new complexes that were not significant in solution may form in the gas phase.

There have been a number of ESI-MS studies in which the drug-DNA complexes detected in the gas phase were consistent with expectations derived from solution studies [10-12]. For example, distamycin binds in a 1:1 complex along AT-rich minor grooves of double-stranded (ds) DNA, but NMR studies suggest that it also binds in a head-to-tail fashion in a 2:1 complex with DNA [13]. Both of these stoichiometries have been observed in ESI-MS experiments [10, 11, 14].

For ESI-MS to be developed as an effective screening method for drug-DNA interactions, it is advantageous to be able to compare the relative binding affinities of drugs for various DNA sequences. This has been achieved using competition experiments to compare the affinities of intercalators for different DNA sequences
[6], and to compare the affinities of different minor groove-binders for different DNA sequences [5, 11, 15].

Most ESI-MS investigations of DNA and drug-DNA complexes have been carried out using negative ion mode. This follows logically from the knowledge that the phosphodiester backbone of DNA has a $\mathrm{pKa}<1$, and is therefore fully ionized under most experimental conditions. There have been several recent reports of ESI mass spectra of DNA acquired using positive ion mode [14, 16-20]. Our own work has shown that negative and positive ion ESI mass spectra of Dm/ dsDNA mixtures obtained under otherwise identical experimental conditions were substantially different [14]. In negative ion spectra, the most abundant ions were from the dsDNA +2 Dm complex, whereas in positive ion mode, the most abundant ions were from the dsDNA +1 Dm complex. On the basis of these observations and in-source collision-induced dissociation experiments (CID), we proposed that the complex containing two Dm molecules is less stable when DNA is positively charged.

In the present work, positive and negative ion ESI mass spectra of complexes of 16 base pair dsDNA with a number of positively charged drug molecules (Figure 1) have been compared to explore the extent to which these effects are influenced by the nature of the binding of the drug to DNA. One of the DNA strands used in this study contained a central AAATA sequence that is a high affinity site for Hoechst 33258 and distamycin [21, 22]. Two relatively GC-rich DNA strands (D1 and D3) were also used, which were therefore not predicted to favor the minor groove-binding mode of interaction 
with dsDNA. The extended aromatic ring systems of $\left[\mathrm{Ru}(\text { phen })_{2} \mathrm{dpq}\right] \mathrm{Cl}_{2}$ and $\left[\mathrm{Ru}(\text { phen })_{2} \mathrm{dpqC}\right] \mathrm{Cl}_{2}$ intercalate between DNA base pairs, and were expected to bind to these sequences [23]. The data presented suggest that different binding modes may be differentially favored in positive and negative ion ESI mass spectra.

\section{Experimental}

\section{Chemicals}

MilliQ water (Millipore, Billerica, MA) was used in all experiments. Ammonium acetate and acetonitrile (HPLC grade) were from Asia-Pacific Specialty Chemicals; Hoechst 33258 and distamycin A were from SigmaAldrich (St. Louis, MO). DNA strands (D1: CCTCTCTGGACCTTCC/GGAAGGTCCAGAGAGG 9764.5 Da; D2: GCTGCCAAATACCTCC/GGAGGTATTTGGCAGC 9763.5 Da; D3: CCTCATGGCCATGACC/ GGTCATGGCCATGAGG 9764.5 Da) were obtained from Geneworks (Adelaide, Australia) as the trityl-on derivatives and purified as previously described [24]. The concentration of single-stranded (ss) DNA was calculated using the Oligonucleotide Properties Calculator [25].

\section{Preparation of dsDNA-Drug Complexes}

The formation of secondary structures within single strands of DNA may introduce error in the concentrations calculated from UV absorbance readings. In order to ensure that equimolar amounts of complementary strands were used in each experiment, single complementary strands were titrated against one another as previously described [14]. The relative amounts of the strands required to form 1:1 dsDNA calculated from these titrations were then used in all experiments. Distamycin and Hoechst 33258 were dissolved in $0.1 \mathrm{M}$ ammonium acetate, $\mathrm{pH} 8.5$, to give stock solutions of 1.0 $\mathrm{mM}$. All solutions were prepared just prior to use to preclude the tendency of the drugs to aggregate in solution over time. The appropriate volumes of complementary DNA strands were freeze-dried using a Savant Speed-Vac (Milford, MA), then redissolved in $20 \mu \mathrm{L}$ of $0.1 \mathrm{M}$ ammonium acetate, $\mathrm{pH}$ 8.5, giving a dsDNA concentration of $1 \mathrm{mM}$. DsDNA was prepared by heating the complementary strands to $20{ }^{\circ} \mathrm{C}$ above their melting temperature (obtained from Oligonucleotide Properties Calculator [25]), in 0.1 M ammonium acetate, $\mathrm{pH}$ 6.8, for $15 \mathrm{~min}$ and annealing by cooling slowly overnight. An aliquot $(60 \mu \mathrm{L})$ of drug solution was added to give the appropriate ratio of drug:dsDNA. Mixtures of dsDNA with $\left[\mathrm{Ru}(\mathrm{phen})_{2} \mathrm{dpq}\right] \mathrm{Cl}_{2}$ or $\left[\mathrm{Ru}(\mathrm{phen})_{2} \mathrm{dpqC}\right] \mathrm{Cl}_{2}$ were prepared as previously described [15]. It should be noted that in our laboratory we have established that no significant differences in the relative abundances of drug-dsDNA complexes are observed when the drugs are added either after or during annealing of the DNA with the non self-complementary 16 mers used in these experiments $[6,14]$.

\section{Mass spectrometry}

All mass spectra were acquired using a Micromass (Wyntheshawe, UK) QTof2 mass spectrometer with a Z-spray probe. The mass analyzer has an $\mathrm{m} / \mathrm{z}$ range of 10 000. DNA ( \pm drug) samples were diluted where necessary with $100 \mathrm{mM}$ ammonium acetate, $\mathrm{pH} 8.5$, giving a final concentration of dsDNA of $10 \mu \mathrm{M}$. These were injected directly using a Harvard Model 22 syringe pump (Natick, MA, USA) at a flow rate of $20 \mu \mathrm{L}$ $\mathrm{min}^{-1}$. Unless otherwise stated, ESI mass spectra were acquired using a probe tip potential of $2600 \mathrm{~V}$, a cone voltage of $50 \mathrm{~V}$, and the source block and desolvation temperatures were 60 and $80{ }^{\circ} \mathrm{C}$, respectively. The transport and aperture were set to 2.0 and 13.0 (arbitrary units), respectively. In experiments where these conditions were varied, details are given in the text. In most experiments, spectra were acquired over the range $\mathrm{m} / \mathrm{z}$ 400-3000. Typically, 30 to 50 scans were summed to obtain representative spectra. The data were calibrated against a standard CsI solution $(750 \mu \mathrm{M})$ over the same $\mathrm{m} / \mathrm{z}$ range. The series of experiments reported here have been repeated at least three times over a period of several months and the differences reported here between positive and negative ion spectra are highly reproducible.

\section{Results and Discussion}

\section{Binding of Distamycin to dsDNA}

In a previous work we showed that positive and negative ion ESI mass spectra of 3:1 mixtures of Dm: dsDNA (D2) acquired under otherwise identical experimental conditions (cone voltage $=50 \mathrm{~V}$ ), provided substantially different information concerning the relative abundances of the drug-DNA complexes [14]. The most abundant ion in the positive ion spectrum was at $\mathrm{m} / z 2049.9$ corresponding to [dsDNA $+1 \mathrm{Dm}]^{5+}$, while the most abundant ion in the negative ion spectrum was at $m / z 1787.6$ corresponding to [dsDNA $+2 \mathrm{Dm}]^{6-}$. Furthermore, when the cone voltage was varied, the relative abundances of ions corresponding to either one or two Dm molecules bound to dsDNA changed. At cone voltages of $30-40 \mathrm{~V}$, ions from dsDNA $+2 \mathrm{Dm}$ predominated in positive ion ESI mass spectra [14]. These spectra were comparable with the negative ion spectrum of the same dsDNA/Dm mixture acquired when the cone voltage was $50 \mathrm{~V}$.

We put forward two proposals to explain these observations: (i) the similarity of the positive ion spectra at $30-40 \mathrm{~V}$ and negative ion spectra at $50 \mathrm{~V}$ may be a consequence of a difference in focusing of positive and negative ions in the source, and/or (ii) the structure of the complex containing $2 \mathrm{Dm}$ molecules bound to dsDNA may be intrinsically less stable when the DNA is positively charged. The positive charge on the DNA most likely resides on the nucleobases [20]; therefore dsDNA sequences that favor binding of drugs with an 
intrinsic positive charge in the vicinity of the charge on the nucleobases would be expected to form complexes that are less stable as positive ions in the gas phase. The latter is also reflected in the fact that the positive ion spectra are more sensitive to changes in cone voltage and temperature than the corresponding negative ion spectra of the same complexes.

In order to provide further understanding of these initial observations, we have compared positive and negative ion ESI mass spectra of complexes of dsDNA with other positively charged molecules: Hoechst 33258 (Hc; minor groove binder) and two ruthenium-based intercalators (Figure 1). In our earlier experiments [14], we used a desolvation temperature of $40{ }^{\circ} \mathrm{C}$. Under these conditions, positive ions in ESI mass spectra of dsDNA/distamycin mixtures were associated with adducts that increased in abundance as the concentration of distamycin increased. In order to minimize these adducts we optimized our conditions further in the present work. Figure 2 shows positive and negative ion ESI mass spectra of 3:1 Dm/D2 mixtures using source block/desolvation temperatures of $40 / 40$ and $60 / 80{ }^{\circ} \mathrm{C}$. The positive ion spectrum $\left(40 / 40{ }^{\circ} \mathrm{C}\right.$; Figure 2a) is comparable with our earlier results using the same DNA sequence and experimental conditions [14]. The most abundant ion in the spectrum was at $m / z 2049.9$ corresponding to $[\mathrm{D} 2+1 \mathrm{Dm}]^{5+}$. When the temperatures were increased to $60 / 80{ }^{\circ} \mathrm{C}$ (Figure $2 \mathrm{~b}$ ), this was still the most abundant ion, but adduct ions were diminished, and the ion at $m / z 1788.2$ corresponding to $[\mathrm{D} 2+2 \mathrm{Dm}]^{6+}$ decreased in abundance. In contrast, the negative ion ESI mass spectra of the 3:1 Dm/D2 mixture were very similar at the two temperatures (Figures $2 \mathrm{c}$ and d), with the most abundant ion at $\mathrm{m} / \mathrm{z} 1786.2$ corresponding to [D2 $+2 \mathrm{Dm}]^{6-}$. In negative ion spectra, adducts that were associated with ions corresponding to Dm/D2 complexes were less pronounced and were further decreased at the higher desolvation temperature. Since this effect was evident in both positive and negative ion spectra, the following studies were carried out using source block and desolvation temperatures of $60^{\circ} \mathrm{C}$ and $80^{\circ} \mathrm{C}$, respectively. A further point of comparison between the positive and negative ion spectra is that the absolute abundance of ions in the positive ion spectra was always higher than in the negative ion spectra. This is generally true for many different biological molecules and probably reflects differences in the ionization/transmission/detection of positive versus negative ions rather than a difference in the relative abundances of the complexes in solution.

\section{Binding of Hoechst 33258 to dsDNA}

Positive and negative ion ESI mass spectra of a 3:1 mixture of Hc with dsDNA (D2) were acquired using a cone voltage of $50 \mathrm{~V}$ and source block and desolvation temperatures of $60{ }^{\circ} \mathrm{C}$ and $80{ }^{\circ} \mathrm{C}$, respectively. In contrast to the results obtained for the Dm/dsDNA mixture, both the positive and negative ion spectra of the 3:1 Hc/dsDNA mixture show that the most abundant drug/dsDNA complex contained one drug molecule (D2 + $1 \mathrm{Hc}$; ion at $\mathrm{m} / \mathrm{z}$ 1697.5 in the negative ion spectrum and 1699.1 in the positive ion spectrum; $z=6$ for both ions). In the negative ion spectrum there were no significant ions from free
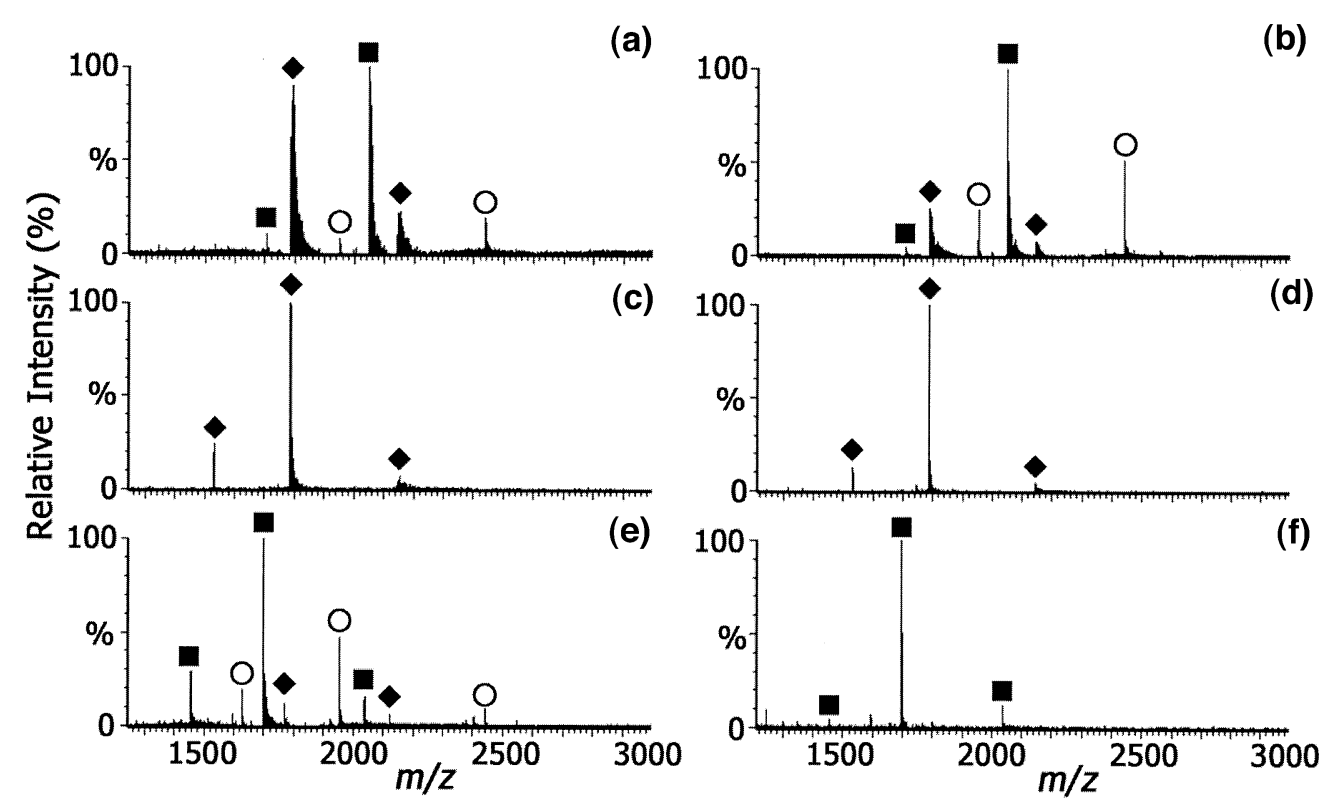

Figure 2. Positive ion and negative ion ESI mass spectra of a 3:1mixture of distamycin or Hoechst 33258 with D2 obtained using different source block and desolvation temperatures. (a) Dm/D2, source/ desolvation $40 / 40{ }^{\circ} \mathrm{C}$, positive ions; (b) Dm/D2, source/desolvation $60 / 80^{\circ} \mathrm{C}$, positive ions; (c) Dm/D2, source/desolvation $40 / 40{ }^{\circ} \mathrm{C}$, negative ions; (d) Dm/D2, source/desolvation $60 / 80{ }^{\circ} \mathrm{C}$, negative ions; (e) $\mathrm{Hc} / \mathrm{D} 2$, positive ions, source block/desolvation temperatures $60 / 80{ }^{\circ} \mathrm{C}$; (f) $\mathrm{Hc} / \mathrm{D} 2$, negative ions, source block/desolvation temperatures $60 / 80^{\circ} \mathrm{C}$; (empty circle) D2; (filled square) $\mathrm{D} 2+1$ drug; (filled diamond) D2 +2 drugs. 
dsDNA or from any other complex. The exclusive presence in this mixture of the 1:1 complex suggests that the binding mode associated with this stoichiometry is highly favored under these experimental conditions. In the positive ion ESI mass spectrum, ions from free DNA were present, suggesting that the D2 + 1 Hc complex was less stable when the DNA was positively charged. Since the total ion counts were higher in positive ion spectra than in negative ion spectra (e.g., 120 arbitrary units in Figure 2e compared with 5 arbitrary units in Figure 2f), then any ions from free dsDNA would have been clearly evident in the negative ion spectra.

It is also of interest to note that in the positive ion spectra of the 3:1 Hc/dsDNA mixture (Figure 2e) the free dsDNA in this spectrum gave an ion where $z=4$, which was not observed in the positive ion ESI mass spectrum of the same dsDNA sequence in the absence of drug acquired under the same experimental conditions, nor was ion from $z=4$ observed in the spectra of free dsDNA for all the sequences examined in this study. The $z=5$ ion of the free dsDNA was also more abundant than in the corresponding spectrum of dsDNA in the absence of drug (data not shown). In contrast for the negative ion spectra (Figure 2f) the relative abundances of the major species $(z=5,6$ and 7$)$ are similar for the free DNA (data not shown). One would expect, given the relatively small size difference between the dsDNA and drug-dsDNA, the same charge state would be observed in each case. Hence, that in the positive ion spectra of the dsDNA-drug complex (Figure 2e), ions from free DNA with $z=4$ and $z=5$ are relatively more abundant than in the corresponding spectrum of free dsDNA without drug added, suggests that the ions from free dsDNA observed in the former case result from dissociation of the drug-dsDNA complex such as in eq 1 and 2:

$$
\begin{aligned}
& {[\mathrm{dsDNA}+\mathrm{Hc}]^{6+} \leftrightarrow[\mathrm{dsDNA}]^{5+}+\mathrm{Hc}^{+}} \\
& {[\mathrm{dsDNA}+\mathrm{Hc}]^{5+} \leftrightarrow[\mathrm{dsDNA}]^{4+}+\mathrm{Hc}^{+}}
\end{aligned}
$$

A further difference between the negative and positive ion spectra of the 3:1 Hc/dsDNA mixture is that in the latter, there were ions of low abundance from D2 +2 Hc (discussed below). Since the relative abundances of ions from dsDNA complexes bearing one or two Dm molecules were shown previously to vary with cone voltage when the desolvation temperature was $40{ }^{\circ} \mathrm{C}$ [14], we investigated the effects of changing cone voltage on ESI mass spectra of 3:1 mixtures of Hc with dsDNA, and repeated our experiments using 3:1 mixtures of Dm with D2 [14], but using the higher desolvation temperature $\left(80{ }^{\circ} \mathrm{C}\right)$. The effect of varying cone voltage on positive and negative ion ESI mass spectra of 3:1 mixtures of either Dm or Hc with D2 (source block and desolvation temperatures 60 and $80{ }^{\circ} \mathrm{C}$, respectively) is shown in Figure 3. The intensities of ions from each complex were summed and plotted as a percent- age of the sum of intensities of all the ions in the spectrum. It should be noted that in all positive and negative ion ESI mass spectra acquired in this work, the only ions of significant abundance were $z=5$ and 6 , with $z=7$ ions of low abundance. The results obtained for the complex(es) with Hoechst 33258 were significantly different from those obtained for the complexes with distamycin. D2 +1 Hc ions were more abundant in both positive and negative ion spectra acquired at all cone voltages from 30-60 V. Importantly, in the negative ion ESI mass spectra, the only significant ions present were from D2 $+1 \mathrm{Hc}$, suggesting that this is a stable complex. Solution and X-ray studies have shown that Hoechst 33258 binds in 1:1 stoichiometry with dsDNA containing $(\mathrm{A} / \mathrm{T})_{4}$ sequences [21, 26-28] spanning 5 base pairs. Since the phosphodiester backbone of DNA is negatively charged in solutions above pH 2, ESI mass spectra of negative ions are expected to be more representative of the complexes found in solution if there are no changes in the equilibrium during ionization and transmission to the detector. The data shown in Figure 3 are consistent with the persistence through all stages of mass analysis of a stable 1:1 complex with negatively charged DNA which has previously been shown to be present by solution spectroscopic techniques. Furthermore, the absence of ions from uncomplexed dsDNA over the cone voltage range 30-60 V demonstrates the stability of this complex.

In contrast, in the positive ion spectra, there were ions of low abundance from $\mathrm{D} 2+2 \mathrm{Hc}$ at all cone voltages. Since both the DNA and Hc are expected to be positively charged under these ionization conditions, the binding of a second Hc molecule to the 16 mer DNA is not likely to arise from non-specific ion pair formation in the gas phase. The positively charged D2 +1 Dm, D2 +2 Dm and D2 + 1 Hc complexes were less stable when the cone voltage was increased than negatively charged complexes. This effect is most likely the result of electrostatic repulsion between the positively charged DNA and the drug molecules.

The question as to whether the dsDNA + 2 Hc complex may have been present in solution prior to analysis by ESI-MS or whether it was formed in the ionization source needs to be considered. Although Hc binds with high affinity to the minor groove of $\mathrm{A} / \mathrm{T}$ sequences, it has also been reported to bind as an intercalator at $\mathrm{G} / \mathrm{C}$ sequences [29]. In solution, if there were D2 molecules with $1 \mathrm{Hc}$ molecule bound in the minor groove at AAATA, and a second Hc molecule intercalated between a G-C base pair, then the ESI mass spectra presented here (see Figure $2 \mathrm{e}$ and $2 \mathrm{f}$ ) suggest that the putative intercalative complex was not stable as negative ions under the experimental conditions (since there were no significant ions from D2 $+2 \mathrm{Hc}$ observed), but was stable under ionization conditions where positively charged DNA was generated. Although we have speculated that a second Hoechst molecule might bind as an intercalator, other binding modes might also be possible either in solution or the gas phase. For example, some unwinding of the 
(a)

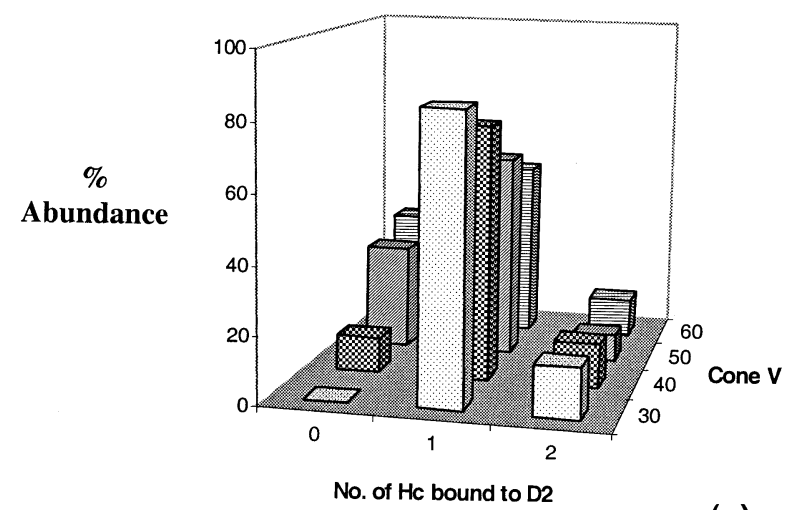

(c)

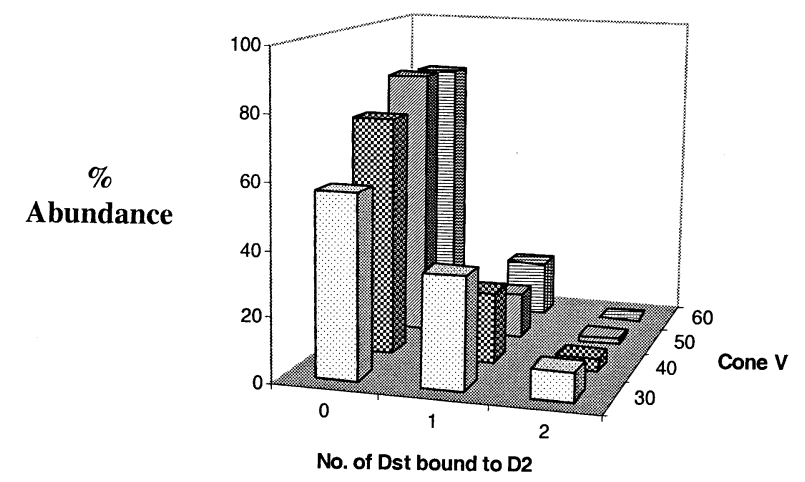

(b)

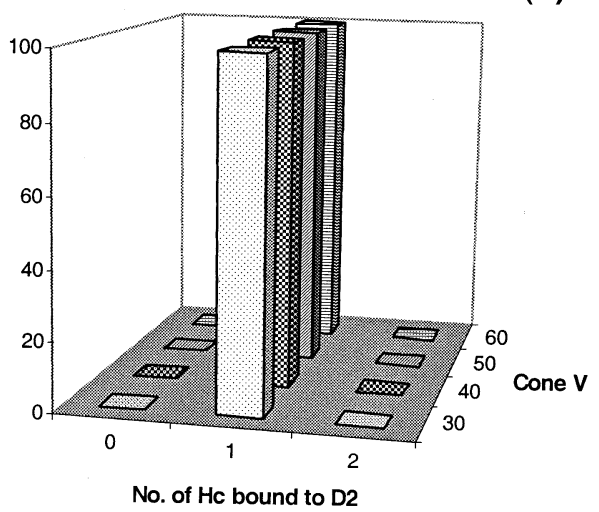

(d)

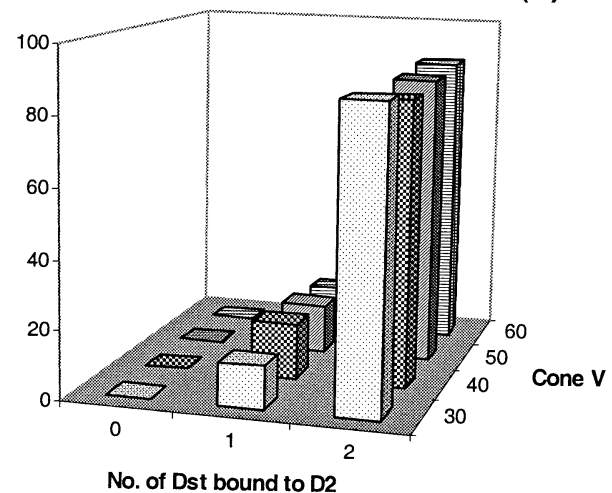

Figure 3. Relative abundances of ions in positive and negative ESI mass spectra of 3:1 mixtures of distamycin or Hoechst 33258 with D2 acquired using different cone voltages. The intensities of ions from a complex were summed and expressed as a percentage of the sum of the intensities of all ions in the spectrum. (a) Hc, positive ions; (b) Hc, negative ions; (c) Dm, positive ions; (d) Dm, negative ions.

positively charged DNA may provide other potential sites for H-bonding not otherwise accessible in fully basepaired DNA. Clearly, other structural studies would be required to confirm the presence of Hc bound to DNA in a mode other than as a minor groove binder if such a mode occurs in solution. Hoechst 33258/dsDNA complexes with 2:1 stoichiometry have been observed previously in negative ion ESI mass spectra. Gabelica and co-workers used an ESI ion trap mass spectrometer to observe a 1:1 complex with a small percentage of 2:1 complex (c.a. 5\%) with the 12 mer duplexes d(GGGG(A/ $\mathrm{T})_{4}$ GGGG)/d(CCCC(T/A) $\left.{ }_{4} \mathrm{CCCC}\right)$. The 2:1 complex was absent when the dsDNA was the self-complementary Dickerson dodecamer d(CGCGAATTCGCG) ${ }_{2}$ [11, 12]. Fluorescence studies did not reveal the presence of the 2:1 complex in solution. They suggested that these results supported the proposal that ESI-MS may be used as a sensitive technique for detecting marginal binding modes.

If a second Hc molecule was bound as an intercalator to $\mathrm{D} 2$, then this binding might be enhanced with sequences of higher G/C content. The sequence selectivities of Hc for 2 different DNA sequences were compared using positive and negative ion ESI mass spectrometry. Of particular interest is the comparison between D2 and D1. D1 is relatively GC-rich and does not contain a minor groove- binding site, while D2 contains a high affinity minor groove site for Hc-binding. Figure 4 shows positive and negative ion ESI mass spectra for a 3:1 mixture of $\mathrm{Hc}$ with D1. These spectra can be compared with the spectra in Figure $2 e$ and $f$ which show the positive and negative ion ESI mass spectra for a 3:1 mixture of Hc with D2. The spectra obtained for the mixtures of Hc with the two DNA sequences are markedly different, and there are also differences between the positive and negative ion spectra for the same sequence. The negative ion spectra most likely represent the components of the solution mixtures in which the DNA is negatively charged, and comparison of the spectra for the 3:1 mixtures of Hc with D1 or D2 reveal clear binding differences. The negative ion ESI mass spectrum (Figure 2f) of the D2 mixture (harboring the high affinity minor groove-binding site) shows only ions from D2 + 1 Hc consistent with solution studies [21, 26-28]. The negative ion spectrum of the 3:1 Hc:D1 mixture (Figure $4 b$ ) contains no significant ions from D1 $+1 \mathrm{Hc}$; the most abundant ions are from free DNA, with an ion of significant abundance from D1 +2 Hc. The presence of ions from the $\mathrm{D} 1+2 \mathrm{Hc}$ suggests that Hc may be bound to D1, a sequence with no minor groove binding site, in a different binding mode, possibly as an intercalator [29]. Alternatively, in the absence of a high affinity minor 

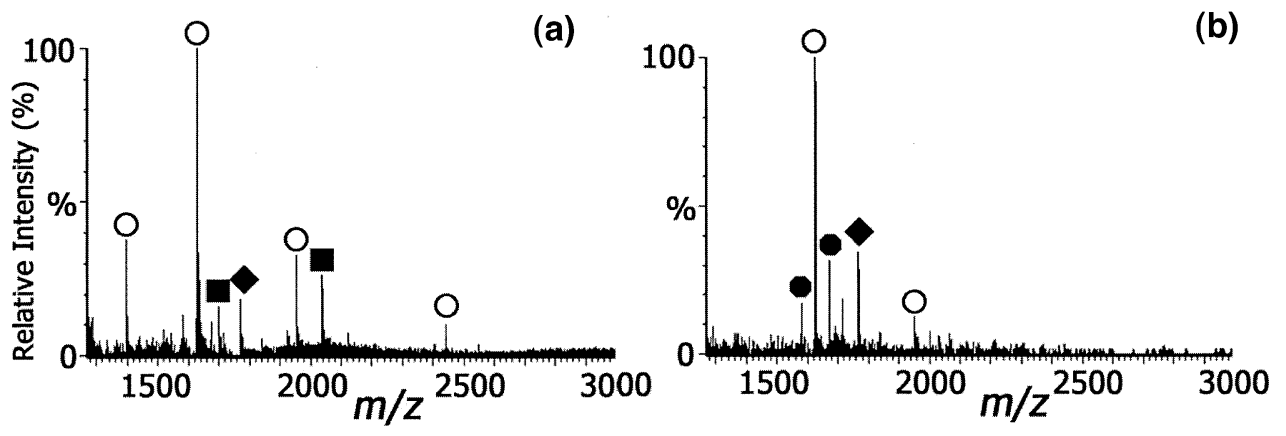

Figure 4. Positive and negative ion ESI mass spectra of mixtures of Hoechst 33258 with D1. (a) 3:1 Hc:D1, positive ions; (b) 3:1 Hc:D1, negative ions; (filled circle) ssDNA; (empty circle) D1; (filled square) D1 $+1 \mathrm{Hc}$; (filled diamond) D1 $+2 \mathrm{Hc}$.

groove binding in the central segment of the sequence site, $2 \mathrm{Hc}$ molecules may be able to bind in a more sterically or electrostatically favorable arrangement. The positive ion spectrum shows ions from both D1 + $1 \mathrm{Hc}$ and D1 +2 Hc suggesting that the structure of D1 $+2 \mathrm{Hc}$ (the only complex observed in the negative ion spectrum) was not as stable when the DNA was positively charged. This appears at first glance to be at odds with the observations for D2 where D2 + 2 Hc occurred only in positive ion ESI mass spectra (Figure 2e). This apparent discrepancy might be explained if $\mathrm{D} 1+2 \mathrm{Hc}$ complexes involve intercalation or another alternate mode of binding for both Hc molecules, while D2 +2 $\mathrm{Hc}$ complexes involve one $\mathrm{Hc}$ molecule binding in the minor groove and one via an alternate mode. In that case for the D1 +2 Hc complex, one of the additional Hc molecules would have been bound in a position that made it less stable when the DNA was positively charged. This possibility is depicted schematically in Figure 5 where it is assumed for simplicity that the second binding mode is intercalation. To our knowledge, there have been no X-ray or solution structures determined for complexes of Hoechst 33258 with D1 or similar sequences.

These experiments do not exclude the possibility that the so-called "second binding mode" is simply nonspecific aggregation of positively charged drugs with DNA during ionization and evaporation of the electrospray droplets. However, that the ESI mass spectra for 3:1 mixtures of Hc with dsDNA of the two sequences were substantially different suggests that these data are a function of different structures formed in solution (or in the gas phase) with D1 and D2 rather than nonspecific binding. (a)

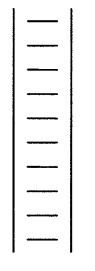

D1
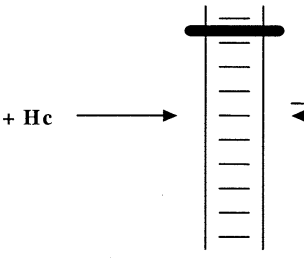

$\mathrm{D} 1+1 \mathrm{Hc}$

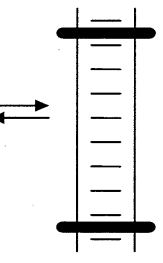

$\mathrm{D} 1+2 \mathrm{Hc}$ (c)

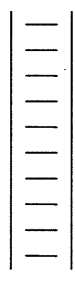

D1

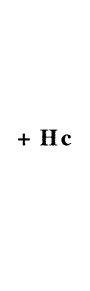

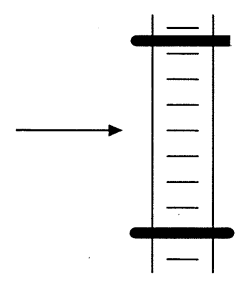

$\mathrm{D} 1+2 \mathrm{Hc}$

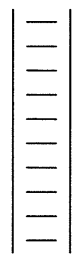

D2 (b)

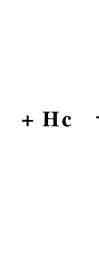

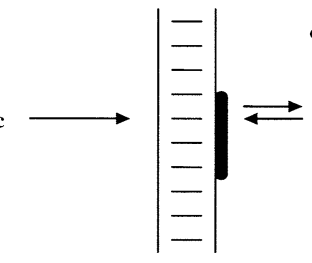

$\mathrm{D} 2+1 \mathrm{Hc}$

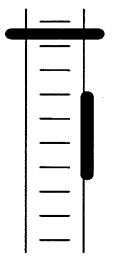

$\mathrm{D} 2+2 \mathrm{Hc}$ (d)

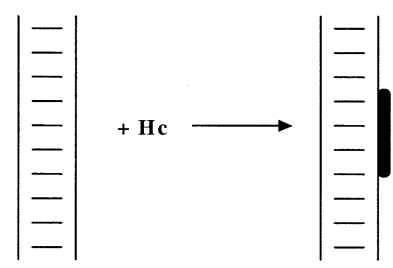

D2

$\mathrm{D} 2+1 \mathrm{Hc}$

Figure 5. Summary of observations from positive and negative ion ESI mass spectra of 3:1 mixtures of Hoechst 33258 with either D1 or D2. (a) Observations from positive ion spectrum of 3:1 Hc: D1. (b) Observations from positive ion spectrum of 3:1 Hc: D2, (c) Observations from negative ion spectrum of 3:1 Hc: D1, (d) Observations from negative ion spectrum of 3:1 Hc: D2. 


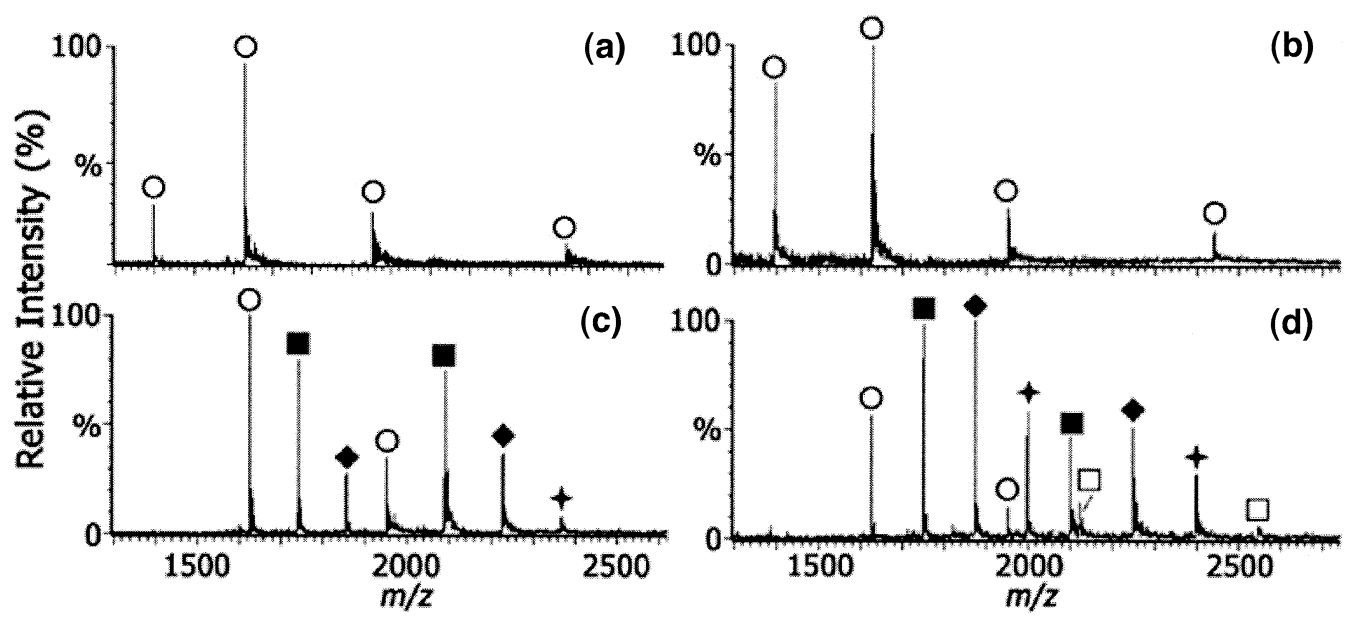

Figure 6. Positive and negative ion ESI mass spectra of mixtures of $\left[\mathrm{Ru}(\mathrm{phen})_{2}(\mathrm{dpq}) \mathrm{Cl}_{2}\right.$ or $\left[\mathrm{Ru}(\mathrm{phen})_{2}(\mathrm{dpqC})\right] \mathrm{Cl}_{2}$ with D3. (a) $3: 1 \quad\left[\mathrm{Ru}(\mathrm{phen})_{2}(\mathrm{dpq})\right] \mathrm{Cl}_{2}: \mathrm{D} 3$, positive ions; (b) $3: 1$ $\left[\mathrm{Ru}(\mathrm{phen})_{2}(\mathrm{dpqC})\right] \mathrm{Cl}_{2}: \mathrm{D} 3$, positive ions; (c) $3: 1\left[\mathrm{Ru}(\mathrm{phen})_{2}(\mathrm{dpq})\right] \mathrm{Cl}_{2}: \mathrm{D} 3$, negative ions; (d) $3: 1$ $\left[\mathrm{Ru}(\text { phen })_{2}(\mathrm{dpqC})\right] \mathrm{Cl}_{2}: \mathrm{D} 3$, negative ions. (empty circle) D3; (filled square) D3+1drug; (filled diamond) D3+2 drugs; (cross) D3+3 drugs; (empty square) D3+ 4 drugs.

\section{Binding of Ru-based intercalators to dsDNA}

Previously, it was shown that dsDNA sequence preferences for binding of $\left[\mathrm{Ru}(\text { phen })_{2} \mathrm{dpq}\right] \mathrm{Cl}_{2}$, $\left[\mathrm{Ru}(\mathrm{phen})_{2} \mathrm{dpqC}\right] \mathrm{Cl}_{2}$ and $\left[\mathrm{Ru}(\text { phen })_{2} \mathrm{dppz}\right] \mathrm{Cl}_{2}$ could be determined by comparing negative ion ESI mass spectra of the complexes with different DNA sequences [15]. NMR studies show that these ligands intercalate between DNA base pairs [23]. In the present work, we have focused on the interactions of $\left[\mathrm{Ru}(\mathrm{phen})_{2} \mathrm{dpq}\right] \mathrm{Cl}_{2}$ and $\left[\mathrm{Ru}(\mathrm{phen})_{2} \mathrm{dpqC}\right] \mathrm{Cl}_{2}$ with D3. Since these compounds both contain $\mathrm{Ru}^{2+}$ they are expected to be attracted to the negatively charged phosphodiester backbone of DNA. Consequently, any significant differences in binding may arise from variations in their relative binding affinities (or sequence preferences) for intercalation.

$\left[\mathrm{Ru}(\text { phen })_{2} \mathrm{dpq}\right] \mathrm{Cl}_{2}$ and $\left[\mathrm{Ru}(\text { phen })_{2} \mathrm{dpqC}\right] \mathrm{Cl}_{2}$ were mixed with D3 in the ratios 1:1, 1.5:1, 3:1 and 6:1 (drug: dsDNA). Figure 6 shows negative and positive ion ESI mass spectra of the 3:1 mixtures. When ESI mass spectra were acquired in positive ion mode (Figures $6 a$ and $b$ ), there were no significant ions present from any dsDNAdrug complex in any of the mixtures; the only ions observed were from free D3 or single strands from D3. In contrast, the negative ion spectra (Figures $6 c$ and d) showed ions from dsDNA-drug complexes with the number of drug molecules bound to DNA increasing with increasing amounts of $\left[\mathrm{Ru}(\text { phen })_{2} \mathrm{dpq}\right] \mathrm{Cl}_{2}$ and $\left[\mathrm{Ru}(\text { phen })_{2} \mathrm{dpqC}\right] \mathrm{Cl}_{2}$ present in the mixtures. The most abundant (negative) ions from dsDNA-drug complexes in the $\left[\mathrm{Ru}(\mathrm{phen})_{2} \mathrm{dpq}\right] \mathrm{Cl}_{2} / \mathrm{D} 3$ mixture were from dsDNA + $1\left[\mathrm{Ru}(\text { phen })_{2} \mathrm{dpq}\right]$, while for $\left[\mathrm{Ru}(\text { phen })_{2} \mathrm{dpqC}\right] \mathrm{Cl}_{2} / \mathrm{D} 3 \mathrm{mix}-$ tures the most abundant negative ions were from dsDNA $+2\left[\mathrm{Ru}(\text { phen })_{2} \mathrm{dpqC}\right]$.

Since DNA is negatively charged in solution and these Ru-based compounds have been shown to bind to DNA using other techniques [23], the negative ion spectra are likely to provide a more accurate picture of the complexes present in solution. Furthermore, previously it has been shown that complexes of well-characterized intercalators with dsDNA can be detected in positive and negative ion ESI mass spectra [6, 14]. It seems likely that dissociation of these compounds occurred during/after formation of positively charged DNA in the ionization source. A similar observation was made for complexes of 16 base pair dsDNA complexed with (positively charged) ethidium bromide (EtBr). Positive ion ESI mass spectra of 3:1 mixtures of ethidium bromide with DNA showed no ions from dsDNA-EtBr complexes. In contrast, negative ion spectra showed ions for free dsDNA and complexes containing 1-5 bound EtBr molecules (data not shown). This compound is known to intercalate into DNA and is used extensively in molecular biology laboratories for DNA staining [1]. Thus while we have speculated that the second Hc molecule observed to bind in the positive ion spectra may result from partial intercalation, the comparison with a classical intercalator such as ethidium bromide supports the notion that the nature of the binding of the second Hc may be in fact more complex.

Furthermore, while no ions from dsDNA-drug complexes were observed in positive ion spectra of the Ru-based intercalators with dsDNA, the presence of the $z=4$ ion from dsDNA in these spectra (Figure 6) may indicate that the complex dissociates during ionization/ transfer to the gas phase according to dissociation channels similar to those proposed for $\mathrm{Hc}$ (eq 1 and 2).

\section{Conclusions}

The experiments reported here indicate that comparison of positive and negative ion ESI mass spectra might reveal information concerning the binding modes of drug mole- 
cules to DNA. By comparing positive and negative ion spectra of Hoechst 33258 with DNA containing a known minor groove binding sequence, a possible alternative binding mode was proposed to occur. The binding of Hoechst 33258 to a sequence that did not allow minor groove binding supported the hypothesis that an alternative binding mode was possible. This alternate binding mode appears to be different to both the side by side binding that occurs when two molecules of distamycin bind to DNA and to classical intercalation since both modes are appear to be unstable under positive ion ionization conditions.

Positive charges in ESI mass spectra of DNA are thought to reside on the nucleobases [30]. The proton affinities of $\mathrm{dA}, \mathrm{dC}$, and $\mathrm{dT}$ are 233.6, 233.2, and 224.9 $\mathrm{kcal} / \mathrm{mol}$, respectively. Therefore, complexes of positively charged compounds with DNA will be unstable when positive ions are formed in the mass spectrometer if their (solution) sequence preference places them in a position where there will be unfavorable interactions with positive charges generated on nucleobases in the ionization source. Furthermore, where there is more than one binding mode available for a drug, the structures of the complexes detected in positive ion spectra may be those in which the positive charge on the drug can be stably accommodated after binding to DNA. For example, no complexes of dsDNA with either $\left[\mathrm{Ru}(\mathrm{phen})_{2} \mathrm{dpqC}\right]$ or $\left[\mathrm{Ru}(\mathrm{phen})_{2} \mathrm{dpq}\right]$ were observed in positive ion spectra, although these compounds are known to bind to DNA. In order to test this proposal it will be necessary to determine an X-ray structure of complexes such as D3/ $\left[\mathrm{Ru}(\mathrm{phen})_{2} \mathrm{dpqC}\right]$ to determine which atoms of the drug molecule are in proximity to atoms on DNA nucleobases that become positively charged in the ionization source.

\section{References}

1. Bischoff, G.; Hoffmann, S. DNA-binding drugs used in medicinal therapies. Curr. Med. Chem. 2002, 9, 321-348.

2. Wemmer, D.E. Ligands recognizing the minor groove of DNA: Development and applications.Biopolymers.2001, 52, 197-211.

3. Geierstanger, B.H.; Wemmer, D.E. Complexes of the minor groove of DNA. Ann. Rev. Biophys. Biomol. Struct. 1995, 24, 463-493.

4. Chaires, J.B.; Satyanarayana, S.; Suh, D.; Fokt, I.; Przewloka, T.; Prie, W. Parsing the free energy of anthracycline antibiotic binding to DNA.Biochemistry 1996, 35, 2047-2053.

5. Wan, K.X.; Shibue, T.; Gross, M.L. Non-covalent complexes between DNA-binding drugs and double-stranded oligodeoxynucleotides: A study by ESI-ion trap mass spectrometry. J. Am. Chem. Soc. 2000, 122, 300-307.

6. Kapur, A.; Beck, J.L.; Sheil, M.M. Observation of daunomycin and nogalamycin complexes with duplex DNA using electrospray ionization mass spectrometry. Rapid Commun. Mass Spectrom. 1999, 13, 2489-2497.

7. Loo, J. Studying non-covalent protein complexes by electrospray ionization mass spectrometry. Mass Spec. Rev. 1997, 16, $1-23$.

8. Hofstadler, S.A.; Griffey, R.H. Analysis of noncovalent complexes of DNA and RNA by mass spectrometry. Chem. Rev. 2001, 101, 377-390.
9. Beck, J.L.; Colgrave, M.L.; Ralph, S.R.; Sheil, M.M. Electrospray ionization mass spectrometry of oligonucleotide complexes with drugs, metals and proteins. Mass Spec. Rev. 2001, 20, 61-87.

10. Gale, D.C.; Smith, R.D. Characterization of noncovalent complexes formed between minor groove-binding molecules and duplex DNA by ESI-MS. J. Am. Soc. Mass Spec. 1995, 6, $1154-1164$

11. Gabelica, V.; De Pauw, E.; Rosu, F. Interactions between antitumor drugs and a double-stranded oligonucleotide studied by ESI-MS. J. Mass Spectrom. 1999, 34, 1328-1337.

12. Rosu, F., Gabelica, V., Houssier, C., De Pauw, E. Determination of affinity, stoichiometry and sequence selectivity of minor groove-binding complexes with double-stranded oligonucleotides. Nucleic Acids Research 2002, 30, e82/1-e82/9.

13. Pelton, J.G.; Wemmer, D.E. Binding modes of distamycin A with d(CGCAAATTTGCG)2 determined by two-dimensional NMR. J. Am. Chem. Soc. 1990, 112, 1393-1399.

14. Gupta, R.; Kapur, A.; Beck, J.L.; Sheil, M.M. Positive ion electrospray ionization mass spectrometry of double-stranded DNA/drug complexes. Rapid Commun. Mass Spectrom. 2001, 15, 2472-2480.

15. Beck, J.L.; Gupta, R.; Urathamakul, T.; Williamson, N.L.; Sheil, M.M.; Aldrich-Wright, J.R.; Ralph, S.F. Probing DNA selectivity of ruthenium metallointercalators using ESI mass spectrometry. Chem. Comm. 2003, 626-627.

16. Iannitti-Tito, P.; Weimann, A.; Wickham, G.; Sheil, M.M. Structural analysis of drug-DNA adducts by tandem mass spectrometry. Analyst. 2000, 125, 627-633.

17. Stephenson, J.L.; Jr.; McLuckey, S.A. Ion-ion proton transfer reactions of multiply-charged oligonucleotide cations. Int. J. Mass Spectrom. Ion Processes 1997, 165/166, 419-431.

18. Schultz, J.C.; Hack, C.A.; Benner, W.H. Mass determination of megadalton-DNA electrospray ions using charge detection mass spectrometry. J. Am. Soc. Mass Spectrom. 1998, 9, 305-313.

19. Schultz, J.C.; Hack, C.A.; Benner, W.H. Polymerase chain reaction products analyzed by charge detection mass spectrometry. Rapid Comm. Mass Spectrom. 1999, 13, 15-20.

20. Sannes-Lowry, K.A.; Mack, D.P.; Hu, P.; Mei, H.-Y.; Loo, J.A. Positive ion electrospray ionization mass spectrometry of oligonucleotides. J. Am. Soc. Mass Spectrom. 1996, 8, 90-95.

21. Spink, N.; Brown, D.G.; Skelly, J.V.; Neidle, S. Sequencedependent effects in drug-DNA interaction: the crystal structure of Hoechst 33258 bound to the d (CGCAAATTTGCG) duplex. Nucleic Acids Res. 1994, 22, 1607-1612.

22. Chen, F-M.; Sha, F. Circular dichroic and kinetic differentiation of DNA binding modes of distamycin. Biochemistry 1998, 37, 11143-11151.

23. Collins, J.G.; Sleeman, A.D.; Aldrich-Wright, J.R.; Greguric, I.; Hambley, T.W. A 1H NMR study of the DNA binding of ruthenium(II) polypyridyl complexes. Inorg. Chem. 1998, 37, 3133-3141.

24. Wickham, G.; Iannitti, P.; Boschenok, J.; Sheil, M.M. Electrospray ionization mass spectrometry of covalent ligand-oligonucleotide adducts: evidence for specific duplex ion formation. J. Mass Spectrom. 1995, 30, S197S203.

25. http://www.basic.nwu.edu/biotools/oligocalc.html.

26. Haq, I.; Ladbury, J.E.; Chowdhry, B.Z.; Jenkins, T.C.; Chaires, J.B. Specific binding of Hoechst 33258 to the d(CGCAAAT TTCGC) $)_{2}$ duplex: Calorimetric and spectroscopic studies. $J$. Mol. Biol. 1997, 271, 244-257.

27. Breusegem, S.Y.; Clegg, R.M.; Loontiens, F. Base-sequence specificity of Hoechst 33258 and DAPI binding to five (A/T) 4 DNA sites with kinetic evidence for more than one high affinity Hoechst 33258-AATT complex. J. Mol. Biol. 2002, 315, 1049-1061. 
28. Loontiens, F.G.; Regenfuss, P.; Zechel, A.; Dumortier, L.; Clegg, R.M. Binding characteristics of Hoechst 3258 with calf thymus DNA, poly\{d(A-T0], and d(CCGGAATTCCGG): Multiple stoichiometries and determination of tight binding with a wide spectrum of affinities. Biochemistry 1990, 29, 9029-9039.

29. Colson, P.; Bailly, C.; Houssier, C. Electric linear dichroism as a new tool to study sequence preference in drug binding to DNA. Biophys. Chem. 1996, 58, 125-140.

30. Greco, F.; Liguori, A.; Sindona, G.; Uccella, N. Gas-phase proton affinity of deoxyribonucleosides and related nucleobases by fast atom bombardment tandem mass spectrometry. J. Am. Chem. Soc. 1990, 112, 9092-9096. 